\title{
Nicotine-induced Attentional Enhancement in Rats: Effects of Chronic Exposure to Nicotine
}

\author{
B. Hahn, and I.P. Stolerman
}

Consistent with human literature, previous studies identified attention-enhancing effects of nicotine in rats, using a 5-choice task. The present study addressed the influence of repeated exposure to nicotine on these effects. Over six weeks, the effects of nicotine $(0.0,0.05$ and $0.2 \mathrm{mg} / \mathrm{kg}$ ) given ten min before sessions were tested each week. In addition, rats were injected daily two hours after sessions. In the first week, when these post-session injections were of saline for all rats, presession nicotine had profound rate-disruptive effects at the larger dose. In weeks 2-6, when half the rats received postsession injections of saline and the other half of nicotine (0.4 $\mathrm{mg} / \mathrm{kg}$ ), the disruptive effects of pre-session nicotine had disappeared and it enhanced attentional performance on all response indices. These effects did not differ significantly between post-session treatment groups or weeks, although they appeared less pronounced in the last two weeks. When tested under modified task parameters in weeks 9 and 10, nicotine $(0.1 \mathrm{mg} / \mathrm{kg})$ robustly enhanced performance in both groups despite continuing daily post-session administration of nicotine or saline. These studies provide evidence that, following tolerance to initial disruptive effects, the nicotineinduced attentional enhancement is stable across lengthy periods of chronic exposure. This is important for potential therapeutic applications of the drug and indicates that these effects can be a continuous motive for smoking behavior.

[Neuropsychopharmacology 27:712-722, 2002] (C) 2002 American College of Neuropsychopharmacology. Published by Elsevier Science Inc.
KEY WORDS: Nicotine; Attention; Serial reaction time, Tolerance, Rats

Among the beneficial effects of nicotine on human cognitive performance, the most consistent findings have been on attention (Stolerman et al. 1995). Such effects have been reported in non-deprived smokers and non-smokers, suggesting that they were not just due to a mere alleviation of withdrawal-induced deficits (Wesnes and Warburton 1984; Foulds et al. 1996; Levin et al. 1998). A

From the Section of Behavioural Pharmacology, Institute of Psychiatry, King's College London, De Crespigny Park, London SE5 8AF, UK.

Address correspondence to: Britta Hahn, M.Sc., Section of Behavioural Pharmacology, Institute of Psychiatry, King's College London, De Crespigny Park, London SE5 8AF, UK. Tel.: +44-(0)207-8480604; Fax; +44-(0)207-848-0579; E-mail: b.hahn@iop.kcl.ac.uk

Received January 18, 2002; revised March 28, 2002; accepted April 1, 2002.

Online publication: 4/4/02 at www.acnp.org/citations/Npp 040402278. range of therapeutic applications of nicotine may develop from this ability to improve attentional functions. Acutely administered nicotine has been shown to reduce performance deficits of patients with Alzheimer's disease in a task of sustained attention (Sahakian et al. 1989; Jones et al. 1992). There is also some indication that nicotine may be beneficial in attention-deficit/hyperactivity disorder and schizophrenia (Levin et al. 1996a, b).

A prerequisite for a chronic therapeutic use of nicotinic compounds as cognitive enhancers is that tolerance does not develop to the effects with repeated administration. When administered to Alzheimer's disease patients over four weeks via transdermal patches, nicotine reduced omission errors in the continuous performance task of attention over the entire course of the treatment (White and Levin 1999). These results are encouraging, but further systematic studies of how nicotine-induced attentional improvements develop with chronic administration are lacking. This may be due to ethical constraints in chronically exposing non-smokers to nicotine 
and the difficulty in interpreting such improvements in smokers. But knowing more about the persistence of nicotine-induced attentional benefits in smokers would also indicate if such effects could contribute to the maintenance of smoking behavior after long periods of drug use.

The effects of nicotine have been examined in several paradigms for assessing attention in rodents. The 5-choice serial reaction time task (5-CSRTT) requires rats to continuously monitor an array of five holes for the occurrence of brief flashes of light presented randomly in one of the locations. In this paradigm, consistent attentional improvements with systemic nicotine have been reported in unlesioned rats (Mirza and Stolerman 1998; Hahn et al. 2002). These improvements were obtained repeatedly in the same subjects, in contrast to earlier findings by Blondel et al. (1999) where increases in response accuracy disappeared after the first administration of nicotine. Results from another study (Grottick and Higgins 2000) using the 5-CSRTT indicated that the effect was even greater after nicotine pre-exposure (daily injections of $0.2 \mathrm{mg} / \mathrm{kg}$ for 20 days or longer).

In a different attention task, requiring rats to detect brief spatially invariant but temporally irregular visual stimuli, chronic injections of nicotine $(0.1 \mathrm{mg} / \mathrm{kg}$ three times per day) improved performance by reducing inappropriate responding in the intertrial interval, with no sign of tolerance even after four weeks of administration. Tolerance developed only to the increase in omission errors observed upon first exposure to nicotine (Nelsen and Goldstein 1972, 1973). Similarly, tolerance did not develop to nicotine-induced improvements in working memory performance in several experiments when rats were chronically infused with nicotine (12 or $5 \mathrm{mg} / \mathrm{kg}$ per day) over three to four weeks (Levin and Simon 1998).

In contrast, tolerance was seen to both the anxiogenic and anxiolytic effects of nicotine after daily injections of nicotine $(0.1 \mathrm{mg} / \mathrm{kg}$ ) over 7 to 14 days (Irvine et al. 1999, 2001), and both tolerance and sensitization occur to its effects on spontaneous locomotor activity in rats. In the latter paradigm, tolerance develops rapidly to the initial nicotine-induced motor depression, thus revealing its motor stimulant effect. The magnitude of the stimulant effect then increases progressively with further daily injections of $0.4 \mathrm{mg} / \mathrm{kg}$ of nicotine (e.g. Clarke and Kumar 1983) and even with injections as infrequent as once weekly (Miller et al. 2001). Thus, behavioral effects of nicotine can display both tolerance and sensitization with chronic exposure, depending on the behavioral measure. This may be related to the fact that brain regions and nicotinic receptor subtypes differ with regard to the rate and extent to which neuroadaptations such as receptor upregulation or desensitization develop (e.g. Marks et al. 1983, 1993; Sanderson et al. 1993; Olale et al. 1997; Wang et al. 1998).
Neurochemically, there are reports that sensitization to the locomotor stimulant effect of nicotine is accompanied by an increased dopamine response in the nucleus accumbens core (Cadoni and Di Chiara 2000) and other dopaminergic projection areas (Marshall et al. 1997). Also, an increase in the density of nicotinic receptors has been reported to coincide with this sensitization process (Ksir et al. 1985, 1987), although the upregulation has also been proposed as an indicator of receptor desensitization and thus a basis for chronic tolerance (Schwartz and Kellar 1985). Some evidence supports this latter hypothesis, for example in mice, tolerance in several behavioral measures and decreases in nicotinic receptor function in some brain regions accompanied increased nicotine binding after chronic nicotine infusion (Marks et al. 1985, 1993). The regime of chronic exposure, i.e. continuous infusion vs. intermittent injections, appears to influence adaptations to behavioral and neuronal responses to nicotine and adds to their complexity (Benwell et al. 1995).

The present study investigated the influence of repeated exposure to nicotine on its effects on attentional performance in the 5-CSRTT. Over two months, the effects of a small and a moderate dose of nicotine were tested weekly against a background of daily post-session injections of either saline or a relatively large dose of nicotine shown to cause neuroadaptations and locomotor sensitization (Clarke and Kumar 1983; Ksir et al. 1985; Benwell and Balfour 1992).

\section{METHODS}

\section{Subjects}

Twenty-four male hooded Lister rats (Harlan Olac, Bicester, UK) weighing 250-300 $\mathrm{g}$ at the beginning of training were housed individually in a temperature ( $20 \pm$ $\left.1^{\circ} \mathrm{C}\right)$ and humidity $(50 \pm 10 \%)$ controlled environment, on a $12 \mathrm{~h}$ light-dark cycle with lights on at 7 A.M. Rats had free access to water and were placed on a foodrestricted diet to maintain them at $85 \%$ of their freefeeding weights. The treatment of animals complied with international guidelines, British Law, and the Code of Practice of the Institute of Psychiatry.

\section{Apparatus}

Aluminum operant chambers measuring $26 \times 26 \times 26$ $\mathrm{cm}$ (Paul Fray Ltd., Cambridge, UK) were housed in sound-insulated and ventilated enclosures. The curved rear wall of each chamber contained five $2.5 \mathrm{~cm}$ square holes, $5 \mathrm{~cm}$ deep and $5 \mathrm{~cm}$ above floor level. At the entrance of each hole a photocell monitored interruptions of a beam of infrared light, and at the rear there was a green light-emitting diode. A food tray, the entrance to which was covered by a hinged flap, was located in the opposite wall, equidistant from each aperture. Illumi- 
nation of each chamber was provided by a houselight situated in its roof. The apparatus and data collection were controlled by software running under RISC OS on an Acorn computer in an adjoining room.

\section{Behavioral Procedure}

The training procedure was similar to that described by Mirza and Stolerman (1998). In the final form of the task, light stimuli of $1 \mathrm{~s}$ duration were presented randomly in one of the holes after an intertrial interval (ITI) of $5 \mathrm{~s}$. If the subject nose-poked into the hole while it was illuminated or within $5 \mathrm{~s}$ after the light had terminated (limited hold), a $45 \mathrm{mg}$ food pellet was delivered into the food tray in the opposite wall of the chamber, and a correct response was registered. A response into any other hole was recorded as an incorrect response and resulted in a time-out of $2 \mathrm{~s}$ duration, during which the house light was extinguished. A failure to respond before the end of the limited hold was registered as an omission error. A new trial began with the initiation of an ITI immediately following a correct response, or after time-outs or limited holds in cases of incorrect responses or omission errors. Responses during intertrial intervals had no programmed consequences and were recorded as anticipatory responses. All training and test sessions lasted $30 \mathrm{~min}$. Rats were trained for four months and experiments started when stable performance of less than $20 \%$ omissions and more than $70 \%$ correct responses on these task parameters was acquired.

The current version of the 5-CSRTT differed from the original version as described by Carli et al. (1983) in several aspects. Omission errors and anticipatory responses were not punished, trials were initiated automatically, not by a panel push by the subject, and the session length was independent of the number of trials completed. The significance of these changes is discussed in Hahn et al. (2002).

Task performance was reflected in the following behavioral measures:

Percentage of correct responses (accuracy) $=100 \times($ correct responses / (correct + incorrect responses)).

Percentage of omission errors (omissions) $=100 \times$ (omission errors / stimuli presented).

Latency of correct responses $=$ the mean time between stimulus onset and a nose-poke in the correct hole.

Anticipatory response rate $=($ total number of responses in ITIs / number of trials) / ITI-length (sec). This yields the number of responses emitted per second, averaged across trials.

\section{Experimental Design}

Experiment 1. Over six weeks, all rats were tested three times per week, every Tuesday, Thursday and
Saturday, and trained on preceding days. In all training sessions, the ITI was $5 \mathrm{~s}$ and the stimulus duration $1 \mathrm{~s}$. In test sessions, the ITI was set to $15 \mathrm{~s}$ and the stimulus duration was reduced to $0.5 \mathrm{~s}$ in order to increase attentional demands and to prevent ceiling effects. Each week, each rat was tested with two doses of nicotine $(0.05$ and $0.2 \mathrm{mg} / \mathrm{kg})$ and saline in a sequence that was randomized for individual subjects.

Prior to tests, rats were randomly allocated to two groups ( $\mathrm{n}=12$ each). In week 1 of testing, all rats received injections of saline about $2 \mathrm{~h}$ after each training or test session. In weeks 2 to 6 but commencing on Saturday of week 1, one group ("chronic saline group") still received daily post-session saline injections, while the other group ("chronic nicotine group") was injected with $0.4 \mathrm{mg} / \mathrm{kg}$ of nicotine instead. These injections were also given on Sundays, when animals were not trained. Table 1 provides an overview over all drug treatments given during Experiment 1.

In the two weeks following this experiment, rats underwent only training sessions. The chronic injection regime of saline or nicotine $(0.4 \mathrm{mg} / \mathrm{kg})$ was continued during this time, but no pre-session injections were given.

Experiment 2. Over a further two weeks (i.e. weeks 9 and 10 since the beginning of tests), during which the chronic injection regimes were continued, the animals were tested on Tuesdays and Fridays with training sessions on other weekdays. In these test sessions, the ITI and stimulus duration were the same as in training sessions, but in two of the four tests a light distractor was presented, which consisted of the house light coming on for $0.5 \mathrm{~s}$ with a frequency of $1 \mathrm{~Hz}$ throughout the session. Pre-session injections of nicotine $(0.1 \mathrm{mg} / \mathrm{kg})$ and saline were tested both with and without the light distractor. Only one dose of nicotine was tested because it was feared that habituation to the distractor might limit the number of drug tests that could be performed. In each separate week of Experiment 2, all rats had one test with and one test without the distractor. The order in which a rat received these treatments within in a week was randomly chosen. In the first week (i.e. week 9), five rats from the chronic saline group and 7 rats from the chronic nicotine group were injected with 0.1 $\mathrm{mg} / \mathrm{kg}$ of nicotine on both tests and the other 12 rats with saline. In the second week (week 10), the drug treatments were reversed for all rats.

\section{Drugs}

Nicotine bitartrate (BDH, Poole, GB) was dissolved in isotonic saline, and the $\mathrm{pH}$ was adjusted to 7 with $\mathrm{NaOH}$ solution. Doses are expressed as those of the base. All injections were given subcutaneously into the flank at a volume of $1 \mathrm{ml} / \mathrm{kg}$. Injections were given 10 min before test sessions and daily chronic injections 
Table 1. Overview of All Drug Treatments Given in Experiment 1

\begin{tabular}{|c|c|c|c|c|}
\hline & \multicolumn{2}{|r|}{ Week 1} & \multicolumn{2}{|c|}{ Weeks 2-6 } \\
\hline & $\begin{array}{l}\text { Acute injections } \\
(10 \text { min pre-session) }\end{array}$ & $\begin{array}{l}\text { Chronic injections } \\
\text { ( } 2 \mathrm{~h} \text { post-session) }\end{array}$ & $\begin{array}{l}\text { Acute injections } \\
\text { (10 min pre-session) }\end{array}$ & $\begin{array}{l}\text { Chronic injections } \\
\text { ( } 2 \mathrm{~h} \text { post-session) }\end{array}$ \\
\hline $\begin{array}{l}\text { Training-sessions } \\
\text { (Mon, Wed, Fri) }\end{array}$ & - & $\begin{array}{l}\text { Chronic saline group: Saline } \\
\text { Chronic nicotine group: Saline }\end{array}$ & - & $\begin{array}{l}\text { Chronic saline group: Saline } \\
\text { Chronic nicotine group: } \\
0.4 \mathrm{mg} / \mathrm{kg} \text { of nicotine }\end{array}$ \\
\hline $\begin{array}{l}\text { Test-sessions } \\
\quad \text { (Tue, Thurs, Sat) }\end{array}$ & $\begin{array}{l}0,0.05, \text { or } 0.2 \mathrm{mg} / \mathrm{kg} \text { of } \\
\text { nicotine }\end{array}$ & $\begin{array}{l}\text { Chronic saline group: Saline } \\
\text { Chronic nicotine group: Saline }\end{array}$ & $\begin{array}{l}0,0.05 \text {, or } 0.2 \mathrm{mg} / \mathrm{kg} \text { of } \\
\text { nicotine }\end{array}$ & $\begin{array}{l}\text { Chronic saline group: Saline } \\
\text { Chronic nicotine group: } \\
0.4 \mathrm{mg} / \mathrm{kg} \text { of nicotine }\end{array}$ \\
\hline
\end{tabular}

circa $2 \mathrm{~h}$ after the termination of tests or training sessions and on Sundays.

\section{Data Analysis}

As in previous work (Mirza and Stolerman 1998; Hahn et al. 2002), percentage data were arcsine transformed, latency data were log transformed, and anticipatory response data were subjected to square root transformation. The purpose was to maximize normal distribution and homogeneity of variances for statistical analyses. In the figures, results are presented as raw values. Data from Experiment 1 were analyzed by 2-factor and 3-factor ANOVA for repeated measures followed by Dunnet's tests. The factors were Group (chronically salinevs. nicotine-treated rats), Drug (doses of nicotine given acutely before sessions) and Week (of testing). Data from Experiment 2 were analyzed by 4 -factor ANOVA based on a linear mixed model. In this model the factors Group (chronically saline- vs. nicotine-treated rats), Drug order (saline in week 1 followed by $0.1 \mathrm{mg} / \mathrm{kg}$ of nicotine in week 2 given before sessions vs. drug injections in the reverse order), Week (i.e. first vs. second exposure to the distractor) and Distractor (houselight steady or coming on and off) were represented by fixed effects. The correlation structure between the repeated measures was accounted for by random effects for rats and for weeks within rats. This analysis provides tests for main effects of factors Group, Drug (saline vs. $0.1 \mathrm{mg} / \mathrm{kg}$ of nicotine), Week, and Distractor and their interaction effects. Paired $t$-tests were performed to compare performance between saline and nicotine states.

The analyses for Experiment 1 were carried out using Unistat 5.0 (Unistat Ltd., London) and the analyses for Experiment 2 using Genstat 5.

\section{RESULTS}

\section{Experiment 1}

Figure 1 suggests that in the first week of testing, when both groups received post-session injections of saline, neither baseline performance nor the effects of nicotine differed substantially between groups. Accordingly, neither the main effect of Group $\left(\mathrm{F}_{1,22}<0.63\right.$, NS) nor the Group X Drug interaction $\left(\mathrm{F}_{2,44}<0.75\right.$, NS) was significant for any of the four measures in 2-way ANOVA with Group as between- and Drug as within-subject factors performed on data from week 1. Significant main effects of Drug were obtained on omission errors $\left(\mathrm{F}_{2,44}=16.8, p<.001\right)$ and anticipatory responding $\left(\mathrm{F}_{2,44}=\right.$ $13.2, p=.001)$, which were due to increases in omissions and decreases of anticipatory responding produced by the $0.2 \mathrm{mg} / \mathrm{kg}$ dose of nicotine.

The effects of nicotine across weeks 2 to 6 , when the nicotine group received daily post-session injections of nicotine $(0.4 \mathrm{mg} / \mathrm{kg})$ and the saline group received the saline equivalent, are summarized in Figure 2. Nicotine dose-dependently enhanced accuracy and reduced omission errors, while the latency of correct responses appeared shortened and anticipatory responding was increased by nicotine. Three-way ANOVA with Group as between- and Drug and Week as within-subject factors carried out on data obtained in weeks 2 to 6 confirmed a highly significant main effect of Drug on each measure $\left(\mathrm{F}_{2,308}>8.5, p<.001\right.$ in all cases $)$. The main effect of Group was not significant on any measure $\left(\mathrm{F}_{1,22}<0.46\right.$, NS) and neither did the effects of Drug interact with Group, although this interaction approached significance on anticipatory responding $\left(\mathrm{F}_{2,308}=2.91, p=.056\right)$. Possibly due to a lower baseline response-rate, the nicotineinduced increase in this measure appeared more pronounced in the nicotine-group than in the saline group.

Figure 3 illustrates the effects of nicotine for separate weeks averaged over both groups, starting at week 2 when chronic treatment with nicotine or saline was commenced. The apparent trend of overall performance levels to improve across weeks was substantiated by significant main effects of Week on accuracy, omission errors and latency $\left.\left(\mathrm{F}_{4,308}\right)>2.87, p<.05\right)$, as well as on anticipatory responding $\left(\mathrm{F}_{4,308}=7.19, p<\right.$ .001). This improvement appeared particularly pronounced under the saline condition, resulting in the impression that the effect of nicotine on performance be- 

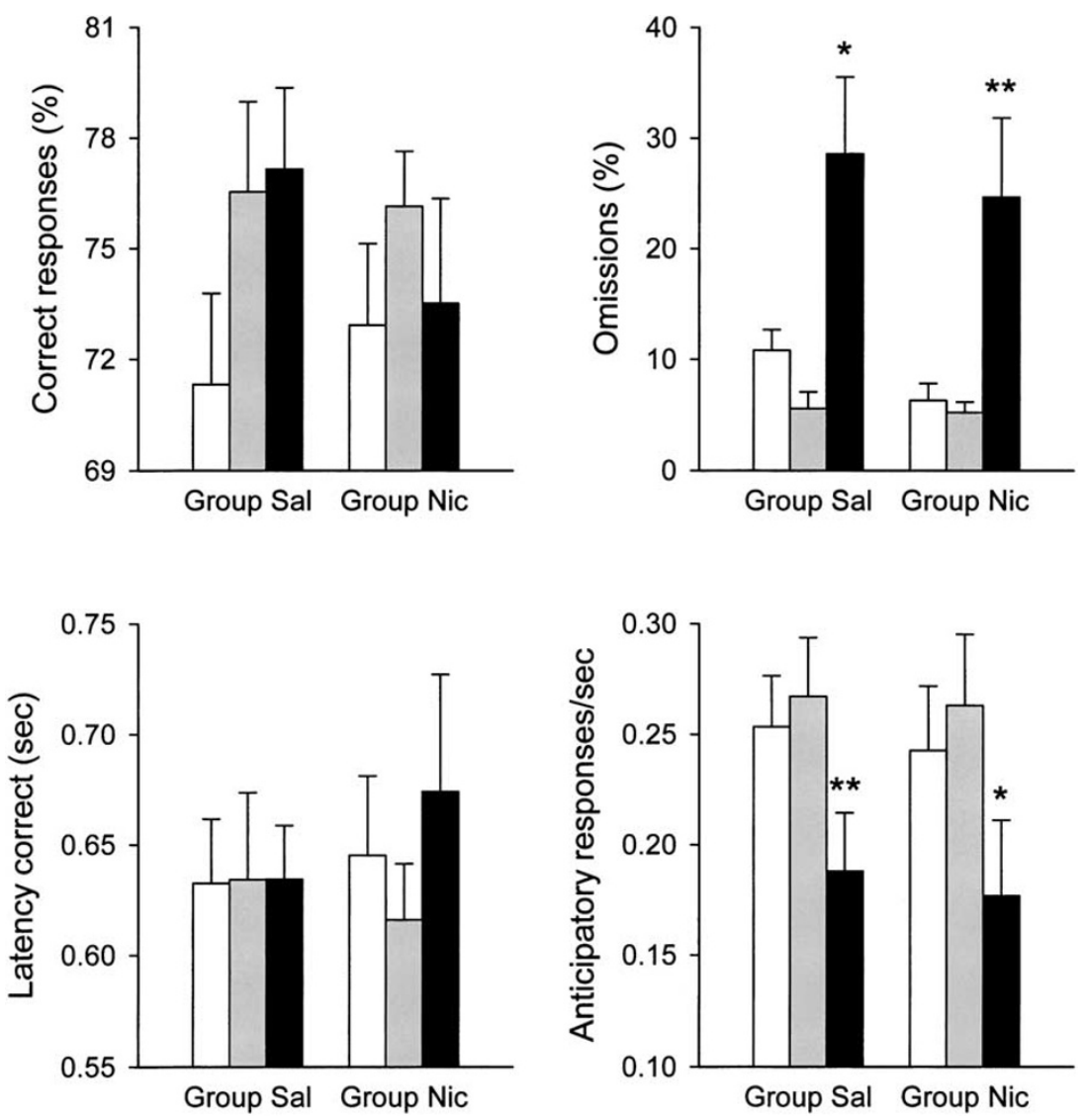

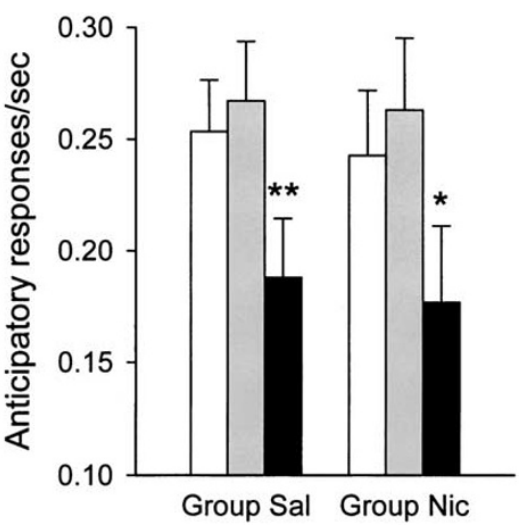

Figure 1. Effects of pre-session injections of saline (white bars) and nicotine (0.05 $\mathrm{mg} / \mathrm{kg}=$ gray bars, $0.2 \mathrm{mg} / \mathrm{kg}=$ black bars) in week 1 of testing, when rats were exposed to nicotine for the first time. All rats were tested with each dose of nicotine and received daily post-session injections of saline. In all later weeks of testing, "Group Sal" ( $\mathrm{n}=12)$ will still receive postsession injections of saline and "Group Nic" ( $\mathrm{n}=12$ ) of $0.4 \mathrm{mg} / \mathrm{kg}$ of nicotine. Bars represent the average performance \pm SEM of 12 rats. Doses of nicotine that produced significant differences compared with saline are marked $\left({ }^{*} p<.05,{ }^{* *} p<.01\right.$; Dunnet's test). Omission errors are shown on a smaller scale than in other figures. came weaker over time. However, the Week $X$ Drug interaction was not significant on any measure $\left(\mathrm{F}_{8,308}<\right.$ 1.13 , NS for all variables).

Significant Group X Week interactions were obtained for omission errors $\left(\mathrm{F}_{4,308}=5.40, p<.001\right)$ and correct response latency $\left(\mathrm{F}_{4,308}=3.17, p<.05\right)$. As can be seen from Figure 4, performance in both measures, averaged over acute treatments, improved rather steadily across weeks in the saline group, while in the nicotine group performance appeared to deteriorate from week 2 to week 4 , after which it improved.

None of the 3-way interactions were significant.

\section{Experiment 2}

From the first week, when rats were exposed to the light distractor for the first time, to the second week, an overall improvement in response accuracy was seen and the anticipatory response rate decreased slightly (data not shown). This result was supported by significant main effects of Week on these measures only (accuracy: $\mathrm{F}_{1,20}=19.3, p<.001$; anticipatory responding: $\mathrm{F}_{1,20}=$ $7.61, p<.05)$. However, neither Distractor nor Drug interacted with Week on any measure (Distractor $X$ Week: $\mathrm{F}_{1,41}<2.02$, NS; Drug X Week: $\mathrm{F}_{1,20}<0.38$, NS for all four variables), indicating that the effects of these manipulations did not differ between the first and the second exposure to the distractor.

Figure 5 shows the effects of acutely administered nicotine $(0.1 \mathrm{mg} / \mathrm{kg})$ in the presence and absence of the light-distractor for rats with a background of either chronic nicotine or chronic saline exposure. Clear overall increases in accuracy and reductions in omission errors and correct response latency can be seen, which were confirmed by significant main effects of Drug on these measures $\left(\mathrm{F}_{1,20}>13.6, p<.001\right.$ for all three variables) but not on anticipatory responding $\left(\mathrm{F}_{1,20}=1.68\right.$, $\mathrm{NS})$. Neither the main effect of Group $\left(\mathrm{F}_{1,20}<0.27\right.$, NS for all four variables) nor the Group X Drug interaction $\left(\mathrm{F}_{1,20}<2.05\right.$, NS for all variables) were significant on any measure, confirming that the chronic injection regime had no effect on overall performance levels or on the acute effects of nicotine. None of the other interactions involving Group as a factor were significant.

The light distractor impaired accuracy and produced slight overall increases in omission errors and response latency, which was confirmed by significant main effects of Distractor on these measures $\left(\mathrm{F}_{1,41}>7.60, p<.001\right.$ for all three variables). On accuracy, nicotine-induced improvements appeared to be more prominent in the presence of the distractor, reversing the distractor-induced impairments, but the Drug $X$ Distractor interaction did not reach significance for this measure $\left(\mathrm{F}_{1,41}=3.17, p=\right.$ 

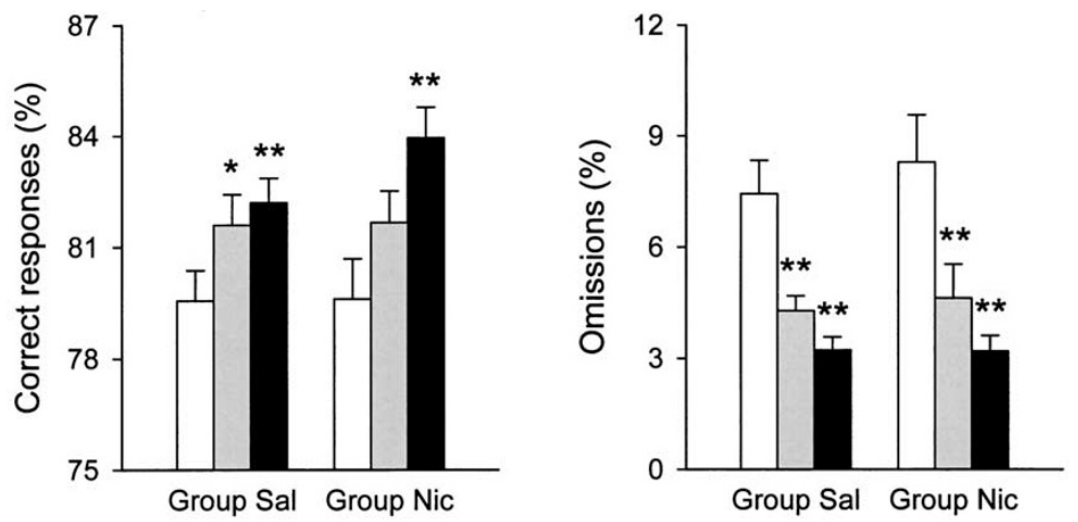

Figure 2. Effects of pre-session injections of saline (white bars) and nicotine $(0.05 \mathrm{mg} / \mathrm{kg}=$ gray bars, $0.2 \mathrm{mg} / \mathrm{kg}=$ black bars) collapsed over weeks 2 to 6 of testing, in which rats in the nicotinegroup received daily post-session injections of nicotine $(0.4 \mathrm{mg} / \mathrm{kg})$ and rats in the saline-group the saline equivalent. The bars represent mean \pm SEM of 60
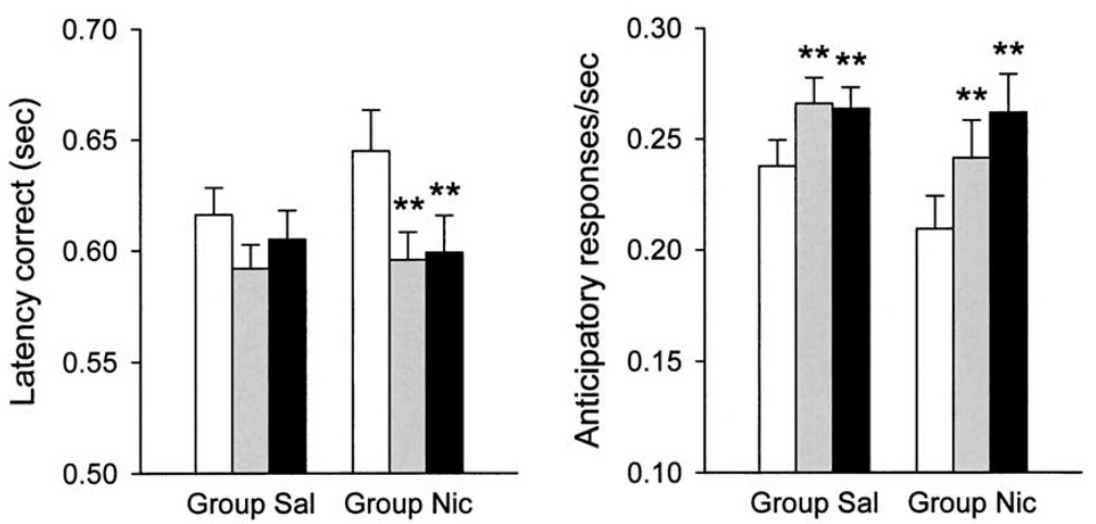
observations, i.e. the performance of 12 rats tested once with each dose of nicotine in each of the five weeks. Doses of nicotine that produced significant differences compared with saline are marked $\left({ }^{*} p<.05,{ }^{* *} p<.01\right.$; Dunnet's test).

.08). No such trends were observed for omission errors and latency $\left(\mathrm{F}_{1,41}<0.78\right.$, NS for both measures). However, the Drug $X$ Distractor interaction was significant for anticipatory responding $\left(\mathrm{F}_{1,41}=8.19, p<.01\right)$, where nicotine appeared to increase responding only in the absence of the distractor in the nicotine group. Baseline responding seemed lower under this condition as compared with the distractor condition in the same group and overall responding in the saline group, and this probably underlay the significant main effect of Distractor on this measure $\left(\mathrm{F}_{1,41}=4.31, p<.05\right)$.

\section{DISCUSSION}

The results of the present study showed biphasic effects of nicotine on attentional performance in the 5-CSRTT with repeated administration. When tolerance had developed to the initial drug-induced disruption of performance, nicotine produced clear attentional improvements. These were still seen after eight weeks of testing and nicotine exposure, regardless of whether animals had been injected with a large dose of nicotine daily or only twice weekly with smaller doses.

In the first week of testing, when the animals were exposed to nicotine for the first time, the largest dose tested $(0.2 \mathrm{mg} / \mathrm{kg})$ produced profound rate-disruptive effects as reflected in increased omission errors and de- creased anticipatory responding. The absence of any decrease in response accuracy by nicotine in this week indicated that these effects do not reflect attentional impairment but rather non-specific response depression. Impairments in the 5-CSRTT were previously observed with $0.4 \mathrm{mg} / \mathrm{kg}$ of nicotine but not with $0.2 \mathrm{mg} / \mathrm{kg}$ (Hahn et al. 2002). However, the previous results were average values derived from a sequence of 15 tests with different doses of nicotine. The fact that in the present study these effects had disappeared by the second week of testing strongly suggests that rapid tolerance to the disruptive effects of $0.2 \mathrm{mg} / \mathrm{kg}$ of nicotine prevented their detection in the earlier study. In a different paradigm requiring the detection of light stimuli, an increase in omission errors has been reported upon first exposure to a dose of nicotine as small as $0.1 \mathrm{mg} / \mathrm{kg}$ (Nelsen and Goldstein 1972). On the following day, after three more exposures to the same dose, this increase was no longer seen.

Such rapid tolerance to the response rate-decreasing effects of nicotine in both signal detection paradigms would be in accordance with findings for the locomotor depressant action of nicotine, to which tolerance can develop after only one exposure to a $0.4 \mathrm{mg} / \mathrm{kg}$ dose (Clarke and Kumar 1983). The suggestion that locomotor depression and ataxia may underlie the nicotineinduced impairments in the 5-CSRTT was made previously, based on the finding that these disruptions 

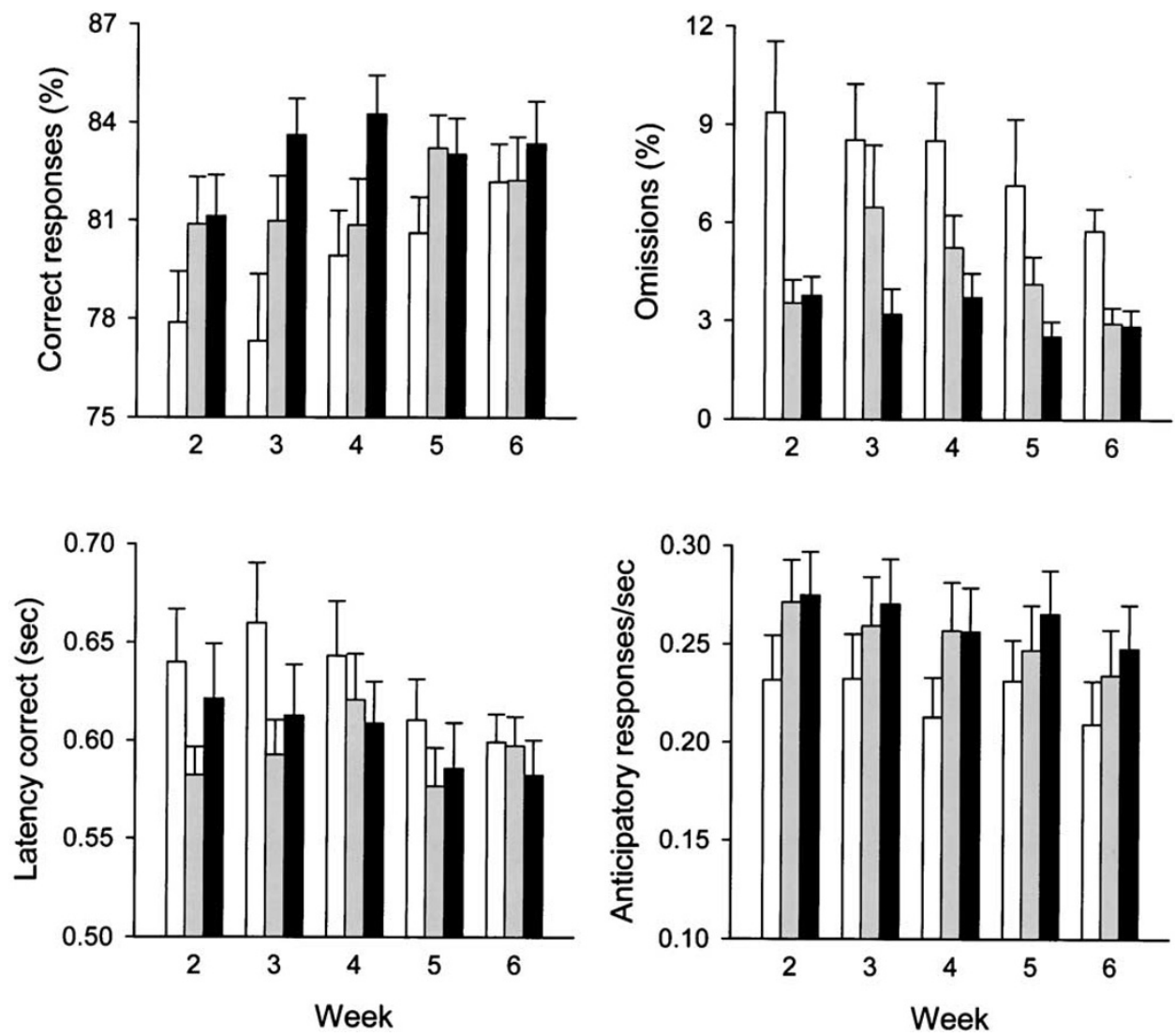

Figure 3. Effects of pre-session injections of saline (white bars) and nicotine $(0.05 \mathrm{mg} /$ $\mathrm{kg}=$ gray bars, $0.2 \mathrm{mg} / \mathrm{kg}=$ black bars) for each of weeks 2 to 6 of testing, collapsed over both chronic treatment groups. Bars represent the average performance \pm SEM of 24 rats. disappeared twenty minutes after the administration of the drug; thus the temporal pattern of both effects matched (Clarke and Kumar 1983; Hahn et al. 2002).

Furthermore, a link between the initial rate-decreasing effects of nicotine and its unpleasant side effects can be suggested. A range of studies in animals and humans suggest also that the aversive effects of nicotine tolerate out rather rapidly (Stolerman 1999). In experiments on the subjective effects of nicotine in smokers and non-smokers, acute tolerance (after four administrations within $2 \mathrm{~h}$ via nasal spray) was seen primarily to the aversive effects of the drug such as "head rush", "jittery", "tension" and "confusion". Non-smokers generally showed profoundly larger responses to nicotine on such measures as compared with smokers, indicating persistent tolerance to these effects after chronic drug exposure (Perkins et al. 1994). Similarly, tolerance was observed to some aversive effects of nicotine in non-smokers over eight days of repeated nicotine gum consumption (Heishman and Henningfield 2000).

It is interesting to note that response indices reflecting the disruptive effects of nicotine in week 1 were also sensitive to manipulations of the subjects' motivational level by varying levels of food deprivation and pre-session access to food (Bizarro and Stolerman 2001). While aversive drug effects may decrease a subject's motivation to display food-rewarded performance, the acute appetite suppressant effects of nicotine could also ex- plain a decreased motivation to earn food reward. It was reported previously that suppression of food intake by nicotine tolerated out with both continuous infusion $(3.4 \mathrm{mg} /$ day) and daily injections $(0.33 \mathrm{mg} / \mathrm{kg})$ of the drug; however in both cases this was seen only after 10 days of exposure (Levin et al. 1987; Caggiula et al. 1989). This result is in contrast to the rapid tolerance that developed to the rate-suppressant effects of nicotine in the present study and makes this explanation appear unlikely.

Response accuracy, the only measure that is not affected by drug effects on the rate and speed of responding, and also correct response latency, was not significantly enhanced by nicotine in week 1, i.e. on the first two exposures to nicotine. This is reminiscent of studies of attentional effects of nicotine in human non-smokers. Although beneficial effects of nicotine on attentional and psychomotor performance have been reported in this population (e.g. Wesnes and Warburton 1984; Foulds et al. 1996), there are also negative reports and in general these effects seem more difficult to demonstrate in nonsmoking subjects (Heishman 1998). The present results conform to the hypothesis that initial disruptive side effects of nicotine may mask its more subtle cognitive enhancing action. Thus, drug effects leading to the nonspecific response depression in week 1 may have overshadowed or blurred beneficial effects of nicotine on stimulus detection, probably by introducing additional 

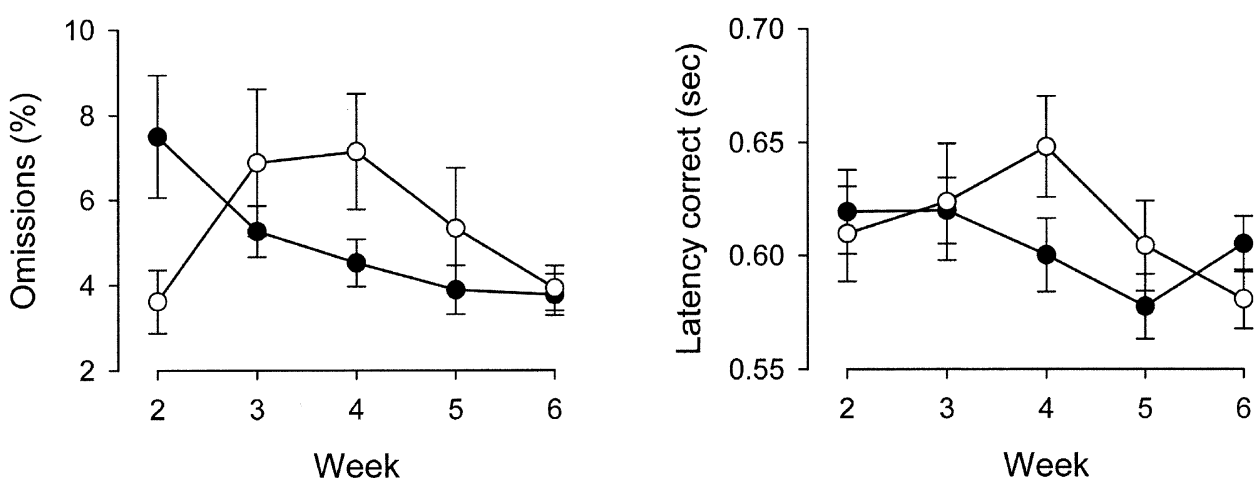

Figure 4. Changes in the percentage of omission errors and correct response latency over weeks 2 to 6 of testing for the chronic saline group $(-)$ and the chronic nicotine group $(\mathrm{O})$. Each data point represents the average performance of 12 rats tested with two doses of nicotine and saline, i.e. mean \pm SEM of 36 observations.

error variability into these measurements, as suggested by Figure 1. In later tests when these rate-disruptive effects had disappeared, the attention-enhancing effects of nicotine could be discerned. Consistent with this possibility is the finding that improvements in short-term recognition memory by nicotine became stronger simultaneously with the development of acute tolerance to some of its aversive effects (Perkins et al. 1994). However, Heishman and Henningfield (2000) did not observe any tolerance to nicotine-induced impairments in the accuracy of working memory and attentional performance that paralleled the development of tolerance to some of its aversive effects.

In weeks 2-6 of testing, when rats underwent the chronic nicotine and saline injection regimes, pre-session injections of nicotine dose-dependently enhanced response accuracy, reduced omission errors and correct response latency and increased anticipatory responding. The same pattern of effects, with the exception of anticipatory responding, was also observed in weeks 9 and 10 with different test parameters, and it closely resembled that obtained in previous experiments (Hahn et al. 2002).

Remarkably, in neither of the present two experiments did these effects differ significantly between treatment groups, although the chronic nicotine group was likely to have undergone more profound neuroadaptive changes than rats that were only intermittently exposed to lower doses of nicotine. The chronic treatment regimes also did not introduce any differences in baseline performance between both groups. Only on anticipatory responding was there a trend toward a difference between groups; in both experiments, the nicotine-induced increase was more pronounced in the chronic nicotine group, although a lower baseline may have contributed to this. Anticipatory responses have no programmed consequences and thus may reflect unspecific motor stimulant effects of nicotine. These stimulant effects may have undergone sensitization to a larger extent in the chronic nicotine group than in the chronic saline group. Similar processes of sensitization with repeated drug exposure may have occurred in human smokers who showed greater responses to nicotine than non-smokers on self-report measures reflecting its stimulating effects ("vigor" and "arousal") (Perkins et al. 1994).

A link between the increase in anticipatory responding by nicotine and its locomotor stimulant effects would allow speculations on underlying neurochemical mechanisms. Nicotine-induced locomotor stimulation is dependent on dopamine release (Di Chiara 2000), and sensitization to this effect is accompanied by sensitization to the dopamine releasing action of nicotine (Benwell and Balfour 1992; Cadoni and Di Chiara 2000; Marshall et al. 1997). While sensitization to the nicotineinduced increase in anticipatory responding would be consistent with an involvement of dopamine neurotransmission, the absence of sensitization to its effects on other response indices may indicate that different mechanisms mediate the effects of nicotine on attentional performance.

In contrast to a previous report (Blondel et al. 1999), tolerance did not develop to the attention-enhancing effects of nicotine. Not only did these effects remain unaffected in rats that were chronically injected with a large dose of nicotine, but they also did not significantly change with weeks of nicotine-exposure. The impression that the effects of nicotine decreased in magnitude over the course of Experiment 1 can most probably be attributed to practice that developed with repeated tests on the same task parameters, causing shifts in baseline performance. When task parameters were changed in Experiment 2, the drug effects were restored in both groups.

It is not clear why improvements in omission errors and response latency with repeated testing should be delayed in chronically nicotine-treated subjects, as was shown by the significant interactions of treatment group with week of testing. From previous experiments on the effects of nicotine on learning processes, its chronic ad- 

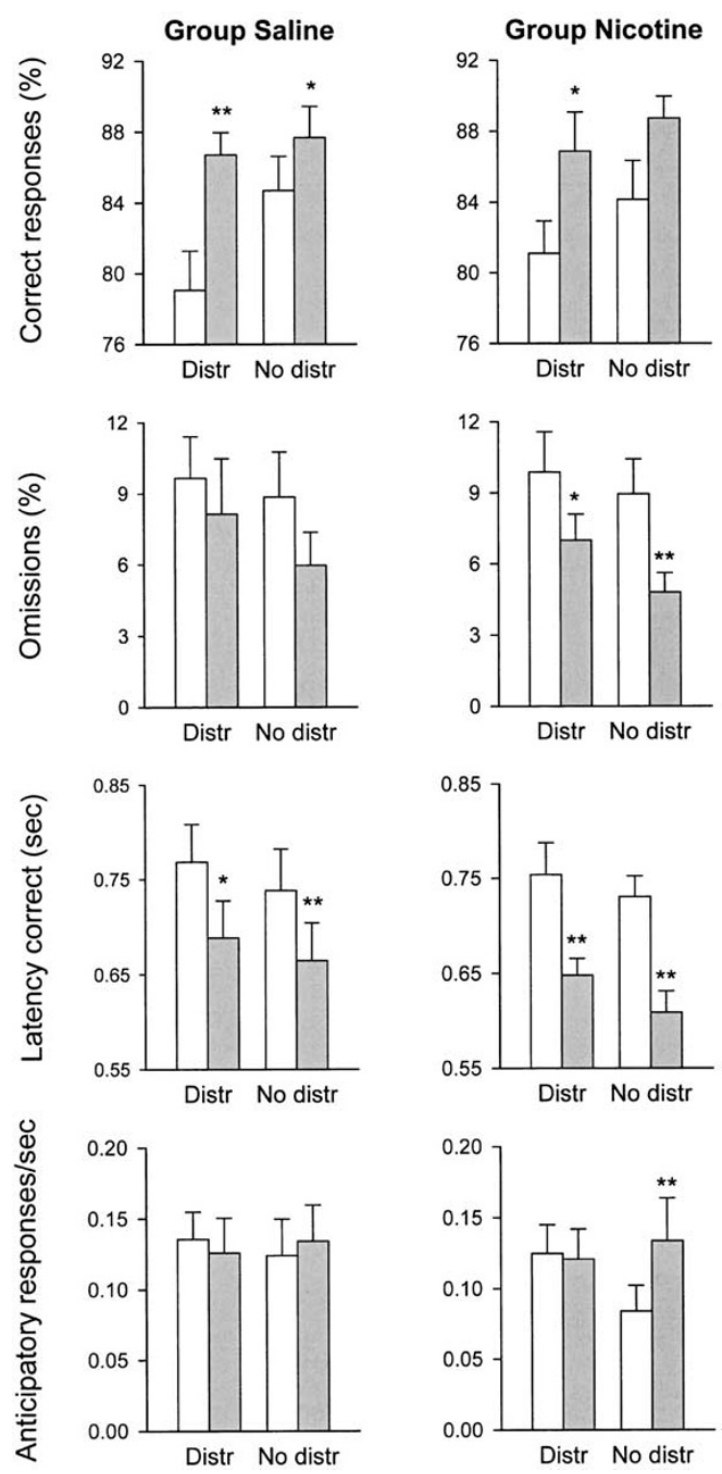

Figure 5. Effects of pre-session injections of saline (white bars) and $0.1 \mathrm{mg} / \mathrm{kg}$ of nicotine (dark gray bars) under distractor (Distr) and training (No distr) conditions. Graphs on the left show data for the chronic saline group and graphs on the right for the chronic nicotine group. Bars represent mean \pm SEM over 12 rats. Significant differences between saline and nicotine are marked $\left({ }^{*} p<.05,{ }^{* *} p<.01\right.$; paired $t$-test). Response accuracy and latency are shown on a smaller scale than in other figures.

ministration would have been expected to facilitate the adaptation to the new task parameters (Levin 1992). Instead, performance appeared to deteriorate from week 2 to 4 in the chronic nicotine group, a trend that could be due to transient performance deficits in the absence of nicotine, later overcome by further practice with testing parameters. The hypothesis was not supported by significant 3-way interactions, but Figure 2, showing data collapsed over weeks 2-6, indicated a trend toward longer response latencies under saline in the chronic nicotine group. However, such deficits not only seemed to vanish with further tests on the parameters of Experiment 1 but also did not appear when test conditions were altered in Experiment 2.

The introduction of the light distractor in Experiment 2 overall caused significant impairments in measures of task performance. However, particularly on omission errors and response latency, these effects were rather small, especially when compared with earlier experiments in which distracting bursts of white noise caused profound disruptions in these measures (Hahn et al. 2002). The light distractor may have been a rather subtle manipulation that only slightly augmented the attentional demands of the task. In the previous study, the distractor condition greatly facilitated the improvements by nicotine, to an extent that it abolished the distractor-induced impairments. In the present study, the effects of nicotine on accuracy and correct response latency were generally larger in Experiment 2 than in Experiment 1 . However, a trend toward a facilitation of the drug effect by the distractor was observed only on accuracy, the measure that was the most affected by the light distractor, although the interaction did not reach significance $(p=.08)$. From the earlier results it was suggested that nicotine may be particularly potent in improving mechanisms of selective attention or the disengaging and shifting of attention from one source of information to another. The present data indicate that this hypothesis is worthy of further investigation.

In summary, after tolerance had developed to the initial rate-disruptive effects of nicotine that are possibly related to ataxia and other noxious side effects upon first exposure, it robustly enhanced attentional performance. Tolerance did not develop to these improvements over two months of chronic or subchronic nicotine exposure. This is encouraging from the perspective of potential therapeutic applications of the drug in chronic disease states. The results also suggest that nicotine-derived attentional benefits may be a persistent factor motivating smoking behavior.

\section{ACKNOWLEDGMENTS}

This work was supported by grants from the MRC. We thank Terry Hewett for technical assistance, Dr. Mohammed Shoaib for valuable discussions, and Dr. Sabine Landau for assistance with statistical analyses.

\section{REFERENCES}

Benwell ME, Balfour DJ (1992): The effects of acute and repeated nicotine treatment on nucleus accumbens dopamine and locomotor activity. Br J Pharmacol 105: 849-856

Bizarro L, Stolerman IP (2001): Different effects of nicotine and motivational level on performance in the rat five- 
choice serial reaction time task. Behav Pharmacol 12 (Suppl 1): S9

Benwell ME, Balfour DJ, Birrell CE (1995): Desensitization of the nicotine-induced mesolimbic dopamine responses during constant infusion with nicotine. Br J Pharmacol 114:454-460

Blondel A, Simon H, Sanger DJ, Moser P (1999): The effect of repeated nicotine administration on the performance of drug-naive rats in a five-choice serial reaction time task. Behav Pharmacol 10:665-673

Cadoni C, Di Chiara G (2000): Differential changes in accumbens shell and core dopamine in behavioral sensitization to nicotine. Eur J Pharmacol 387:R23-R25

Caggiula AR, Epstein LH, Stiller R (1989): Changing environmental cues reduces tolerance to nicotine-induced anorexia. Psychopharmacology (Berl) 99:389-392

Carli M, Robbins TW, Evenden JL, Everitt BJ (1983): Effects of lesions to ascending noradrenergic neurones on performance of a 5-choice serial reaction task in rats; implications for theories of dorsal noradrenergic bundle function based on selective attention and arousal. Behav Brain Res 9:361-380

Clarke PB, Kumar R (1983): The effects of nicotine on locomotor activity in non-tolerant and tolerant rats. Br J Pharmacol 78:329-337

Di Chiara G (2000): Role of dopamine in the behavioural actions of nicotine related to addiction. Eur J Pharmacol 393:295-314

Foulds J, Stapleton J, Swettenham J, Bell N, McSorley K, Russell MA (1996): Cognitive performance effects of subcutaneous nicotine in smokers and never-smokers. Psychopharmacology (Berl) 127:31-38

Grottick AJ, Higgins GA (2000): Effect of subtype selective nicotinic compounds on attention as assessed by the five-choice serial reaction time task. Behav Brain Res 117:197-208

Hahn B, Shoaib M, Stolerman IP (2002): Nicotine-induced enhancement of attention in the five-choice serial reaction time task: the influence of task-demands. Psychopharmacology (Berl) 162:129-137

Heishman SJ (1998): What aspects of human performance are truly enhanced by nicotine? Addiction 93:317-320

Heishman SJ, Henningfield JE (2000): Tolerance to repeated nicotine administration on performance, subjective, and physiological responses in nonsmokers. Psychopharmacology (Berl) 152:321-333

Irvine EE, Cheeta S, File SE (1999): Time-course of changes in the social interaction test of anxiety following acute and chronic administration of nicotine. Behav Pharmacol 10:691-697

Irvine EE, Cheeta S, File SE (2001): Tolerance to nicotine's effects in the elevated plus-maze and increased anxiety during withdrawal. Pharmacol Biochem Behav 68:319325

Jones GM, Sahakian BJ, Levy R, Warburton DM, Gray JA (1992): Effects of acute subcutaneous nicotine on attention, information processing and short-term memory in Alzheimer's disease. Psychopharmacology (Berl) 108: 485-494

Ksir C, Hakan R, Hall DP Jr, Kellar KJ (1985): Exposure to nicotine enhances the behavioral stimulant effect of nicotine and increases binding of [3H]acetylcholine to nicotinic receptors. Neuropharmacology 24:527-531

Ksir C, Hakan RL, Kellar KJ (1987): Chronic nicotine and locomotor activity: influences of exposure dose and test dose. Psychopharmacology (Berl) 92:25-29

Levin ED (1992): Nicotinic systems and cognitive function. Psychopharmacology (Berl) 108:417-431

Levin ED, Conners CK, Sparrow E, Hinton SC, Erhardt D, Meck WH, Rose JE, March J (1996a): Nicotine effects on adults with attention-deficit/hyperactivity disorder. Psychopharmacology (Berl) 123:55-63

Levin ED, Morgan MM, Galvez C, Ellison GD (1987): Chronic nicotine and withdrawal effects on body weight and food and water consumption in female rats. Physiol Behav 39:441-444

Levin ED, Wilson W, Rose JE, McEvoy J (1996b): Nicotinehaloperidol interactions and cognitive performance in schizophrenics. Neuropsychopharmacology 15:429-436

Levin ED, Conners CK, Silva D, Hinton SC, Meck WH, March J, Rose JE (1998): Transdermal nicotine effects on attention. Psychopharmacology (Berl) 140:135-141

Levin ED, Simon BB (1998): Nicotinic acetylcholine involvement in cognitive function in animals. Psychopharmacology (Berl) 138:217-230

Marks MJ, Burch JB, Collins AC (1983): Effects of chronic nicotine infusion on tolerance development and nicotinic receptors. J Pharmacol Exp Ther 226:817-825

Marks MJ, Stitzel JA, Collins AC (1985): Time course study of the effects of chronic nicotine infusion on drug response and brain receptors. J Pharmacol Exp Ther 235:619-628

Marks MJ, Grady SR, Collins AC (1993): Downregulation of nicotinic receptor function after chronic nicotine infusion. J Pharmacol Exp Ther 266:1268-1276

Marshall DL, Redfern PH, Wonnacott S (1997): Presynaptic nicotinic modulation of dopamine release in the three ascending pathways studied by in vivo microdialysis: comparison of naive and chronic nicotine-treated rats. J Neurochem 68:1511-1519

Miller DK, Wilkins LH, Bardo MT, Crooks PA, Dwoskin LP (2001): Once weekly administration of nicotine produces long-lasting locomotor sensitization in rats via a nicotinic receptor-mediated mechanism. Psychopharmacology (Berl) 156:469-476

Mirza NR, Stolerman IP (1998): Nicotine enhances sustained attention in the rat under specific task conditions. Psychopharmacology (Berl) 138:266-274

Nelsen JM, Goldstein L (1972): Improvement of performance on an attention task with chronic nicotine treatment in rats. Psychopharmacologia 26:347-360

Nelsen JM, Goldstein L (1973): Chronic nicotine treatment in rats. 1. Acquisition and performance of an attention task. Res Commun Chem Pathol Pharmacol 5:681-693

Olale F, Gerzanich V, Kuryatov A, Wang F, Lindstrom J (1997): Chronic nicotine exposure differentially affects the function of human alpha3, alpha4, and alpha7 neuronal nicotinic receptor subtypes. J Pharmacol Exp Ther 283:675-683

Perkins KA, Grobe JE, Fonte C, Goettler J, Caggiula AR, Rey- 
nolds WA, Stiller RL, Scierka A, Jacob RG (1994): Chronic and acute tolerance to subjective, behavioral and cardiovascular effects of nicotine in humans. J Pharmacol Exp Ther 270:628-638

Sahakian B, Jones G, Levy R, Gray J, Warburton D (1989): The effects of nicotine on attention, information processing, and short- term memory in patients with dementia of the Alzheimer type. Br J Psychiatry 154: 797-800

Sanderson EM, Drasdo AL, McCrea K, Wonnacott S (1993): Upregulation of nicotinic receptors following continuous infusion of nicotine is brain-region-specific. Brain Res 617:349-352

Schwartz RD, Kellar KJ (1985): In vivo regulation of [3H]acetylcholine recognition sites in brain by nicotinic cholinergic drugs. J Neurochem 45:427-433
Stolerman IP, Mirza NR, Shoaib M (1995): Nicotine psychopharmacology: addiction, cognition and neuroadaptation. Med Res Rev 15:47-72

Stolerman IP (1999): Inter-species consistency in the behavioural pharmacology of nicotine dependence. Behav Pharmacol 10:559-580

Wang F, Nelson ME, Kuryatov A, Olale F, Cooper J, Keyser K, Lindstrom J (1998): Chronic nicotine treatment upregulates human alpha3 beta2 but not alpha3 beta 4 acetylcholine receptors stably transfected in human embryonic kidney cells. J Biol Chem 273:28721-28732

Wesnes K, Warburton DM (1984): Effects of scopolamine and nicotine on human rapid information processing performance. Psychopharmacology (Berl) 82:147-150

White HK, Levin ED (1999): Four-week nicotine skin patch treatment effects on cognitive performance in Alzheimer's disease. Psychopharmacology (Berl) 143:158-165 